\title{
Reduce Evaporation Losses from Water Reservoirs
}

\author{
${ }^{1}$ Khudair abass dawood , ${ }^{2}$ Farhan Lafta Rashid , ${ }^{3}$ Ahmed Hashim \\ ${ }_{1,2}$ Ministry of Science and Technology, Iraq \\ ${ }^{3}$ Babylon University, Iraq
}

\begin{abstract}
Evaporation suppression is the reduction of evaporation bycontrolling the rate at which water vapor escapes from water surfaces. The need for water saving is greatest in areas of little rainfall and low runoff. Water losses by evaporation from storage reservoirs must be minimized for greatest utility of limitedsupplies.

Using trash of polyethylene with different densities $\left(800,875\right.$ and $\left.900 \mathrm{~kg} / \mathrm{m}^{3}\right)$ as floating cover to the water filling cylindrical container with $8 \mathrm{~cm}$ diameter led to reduce the evaporation rate. A suitable trash density of $800 \mathrm{~kg} / \mathrm{m}^{3}$ gave reduction in evaporation rate of $57 \%$ from the theoretical results calculated using equation (4) which is a good result if compared with previous researches.
\end{abstract}

Keywords: evaporation rate, evaporation suppression, water reservoir.

\section{Introduction}

Evaporation of water from reservoirs, rivers, and agricultural fields results in major losses of critical water resources, especially in arid regions of the world. In arid regions, evaporation can account for as much as 25 to $30 \%$ of the total consumptive use of surface water. Because evaporation is such a large part of the wa-ter budget in arid regions, evaporation suppression has been studied for decades. Research has shown that surfactants, which modify the surface tension of the water surface, are very effective in the laboratory in sup-pressing evaporation. Recent research has shown that environmentally innocuous surfactant monolayers covering water surfaces can reduce the rate of evaporation by as much as 40 to $70 \%$, resulting in substantial water resource savings[1].

Annual loss of water from storages through evaporation can potentially exceed 40 per cent of water stored. Nationally more than $7000 \mathrm{GL}$ is stored in over two million on-farm storages, with a further 80000 GL held in registered large dams .

The loss of water causes lost agricultural production, leading to financial stress for some farmers particularly in times of drought. Low water levels also lead to water restrictions being imposed on urban regions. Reducing the amount of water lost to evaporation would improve water security and lead to increased irrigation production $[2]$.

Hardy [3] was the first to suggest that monolayers were formed from polar molecules consisting of a hydrophobic (water-repelling) and a hydrophilic (water-attracting) part, and hence that the monolayer molecules were orientated with the hydrophillic part (a functional group such as a hydroxyl-OH or carboxyl- $\mathrm{COOH}$ ) buried in the water, and the hydrophobic part (a hydrocarbon structure)tending to leave the water. Conclusive support for this hypothesis of orientation

was provided by Langmuir [4].

Finn and Barnes [5] use a suspended covers which are horizontal sail-like structures that are suspended over water surfaces and aresupported externally by steel cables and poles. Suspension systems can be characterized by their spanand their cover weight. The cover material can vary from porous shade screens to impermeable plastic [6]. The cover reduces evaporation byblocking incoming solar radiation incident upon the water surface, thus reducing thermal energy inputinto the reservoir surface waters, which in turn reduces the water surface temperature and the potentialfor evaporation. The covers also reduce surface wind action by lowering the vapour pressure gradientover the water. The covers can also trap water vapour at the water surface that would otherwise bereplaced by dry air.

Howard and Schmidt [7] uses a Floating covers include modular and flat sheet covers that float on the water surface. They reflect aproportion of the incoming solar radiation and act as physical barriers to the passage of water vapourboth vertically and horizontally. Unlike suspended covers, the floating covers are supported by thewater itself. However, they do need to be fixed on the water surface using some form of anchoringmechanism when used on large dams. While most floating cover products are designed to withstandstrong wind forces, it is evident they have been designed predominantly for small storages and haven ot been rigorously tested on larger reservoirs. 
Heymann and Yoffe[8, 9] studied "the stabilityof multimolecular films of hydrocarbon oils, containingspreaders, on water surfaces" and found that polymerizedspreaders form thick films of oil that are muchmore stable than other spreaders; some last as long as 18 months if they are kept free from dust.

In this paper trash of polyethylene with different densities $(800,875$ and $900 \mathrm{~kg} / \mathrm{m} 3)$ used as floated cover to the water filling the container in order to reduce the evaporation rate.

\section{Theoretical Analysis}

\section{Ficks' Law of Diffusion and Stefan Problem[10]:}

Consider a non reacting gas mixture of species A and B. Ficks' Law describes the rate at which one species diffuses through other. For the case of one dimensional binary diffusion, Ficks' Law on a mass basis is:

$m_{A}^{\prime \prime}=Y_{A}\left(m_{A}^{\prime \prime}+m_{B}^{\prime \prime}\right)-\rho D_{A B} \frac{d Y_{A}}{d x}$

Where $m_{A}^{\prime \prime}=\frac{m_{A}}{A}$ is the mass flux of species A $\left(\mathrm{kg} / \mathrm{m}^{2} . s\right)$

$Y_{A}$ is the mass fraction

$D_{A B}$ is binary diffusivity $\left(\mathrm{m}^{2} / \mathrm{s}\right)$

Stefan assumes the following assumptions for equation (1):

1. Gas B is insoluble in liquid $\mathrm{A}\left(m_{B}^{\prime \prime}=0\right)$

2. Steady state.

3. Liquid level is constant or interface regresses so slow, that its movement can be neglected.

$$
\begin{aligned}
& m_{A}^{\prime \prime}=Y_{A} m_{A}^{\prime \prime}-\bar{\rho} D_{A B} \frac{d Y_{A}}{d x} \\
& m_{A}^{\prime \prime}-Y_{A} m_{A}^{\prime \prime}=-\bar{\rho} D_{A B} \frac{d Y_{A}}{d x}
\end{aligned}
$$

Rearrange equation (2) and integrate:

$$
\begin{aligned}
& \int_{x=0}^{x} \frac{m_{A}^{\prime \prime}}{-} d x D_{A B} \int_{Y A, i}^{Y A} \frac{-1}{\left(1-Y_{A}\right)} d Y_{A} \\
& \frac{m_{A, x}^{\prime \prime}}{\rho D_{A B}}=\ln \frac{\left(1-Y_{A}\right)}{\left(1-Y_{A, i}\right)} \\
& Y_{A}=1-\left(1-Y_{A, i}\right) \exp \left(\frac{m_{A}^{\prime \prime \prime} x}{\rho D_{A B}}\right)
\end{aligned}
$$

\section{Boundary conditions:}

At $\mathrm{x}=\mathrm{L} Y_{A}=Y_{A, \infty}$ for equation (3):

$$
m_{A}^{\prime \prime}=\frac{\bar{\rho} D_{A B}}{L} \ln \frac{\left(1-Y_{A, \infty}\right)}{\left(1-Y_{A, i}\right)}
$$

Equation (4) can be used to calculate the theoretical evaporation rate per unit area

Where $m_{A}:$ is evaporation rate per unit area 
$\rho$ is the average gas density in the container (Fig.(1)) and can be calculated from:

$$
\bar{\rho}=\frac{P}{\left(R_{u} / M \bar{W}\right) T}
$$

$\mathrm{P}$ is the atmospheric pressure

\section{$R_{u} \quad$ is Universal Gas Constant \\ $\mathrm{L}$ is the interface depth from the top of container}

$\mathrm{T}$ is Gas Temperature

$$
\stackrel{-}{M W}=0.5\left(M W_{m i x, i}+M W_{m i x, \infty}\right)
$$

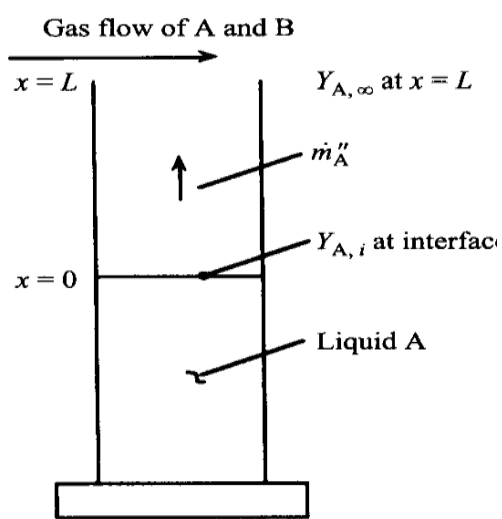

Figure(1) Diffusion of Vapor A through a Stagnant Column of Gas B, i.e., the Stefan Problem

\section{Experimental Part}

Figure (1) shows the container ( $8 \mathrm{~cm}$ diameter, filled with water at depth of $3 \mathrm{~cm}$ from the top of the container) at which our experiments were take place, using trash of polyethylene for different densities ranged from 800 to $900 \mathrm{~kg} / \mathrm{m}^{3}$ putted in a float layout at the interface $(\mathrm{x}=0)$ to reduce water evaporation from the surface and take the measurements which involve temperature and net weight of the water in the container by using sensitive weight balance, in each measurement write down the time from starting evaporation in order to divide the net weight on the time to give evaporation time.

\section{Results and Discussions}

Calculations of evaporation rate for different trash density were obtained and compared with theoretical results obtained from equation (4), we can see from figure (2) that shows the relationship between evaporation rate with temperature, an increase in water temperature led to an increase in evaporation rate, also minimum evaporation rate take place with using trash of lower density $\left(800 \mathrm{~kg} / \mathrm{m}^{3}\right)$ and increased with increasing trash density. Figure(3) shows the relationship between evaporation rate with time, one can observe that an increase in evaporation time will increase the evaporation rate, also minimum evaporation rate take place with trash of low density $\left(800 \mathrm{~kg} / \mathrm{m}^{3}\right)$ and increase with increasing trash density. 


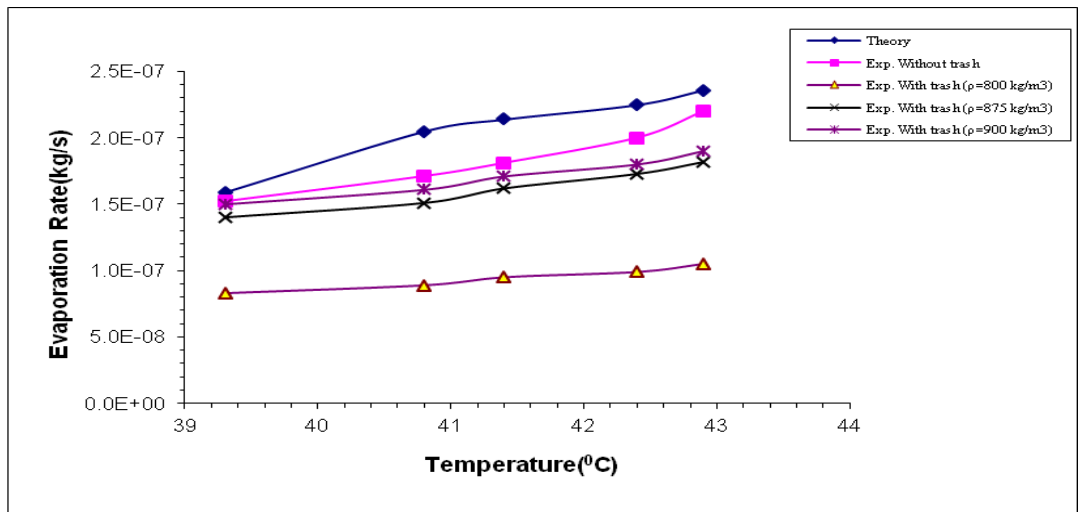

Figure (2) Variation of Evaporation Rate with Temperature

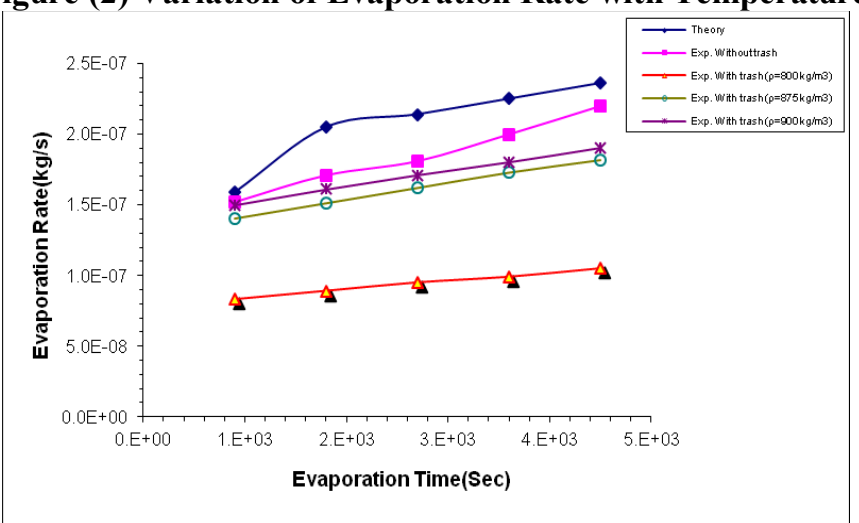

Figure (3) Variation of Evaporation Rate with Time

\section{Conclusions}

From the present work, we can deduce the following conclusion:

1. An increase in evaporation time and temperature will lead to increase in evaporation rate.

2. Reducing the trash density will reduce the evaporation rate.

3. Using trash density of $800 \mathrm{~kg} / \mathrm{m}^{3}$ will reduce evaporation rate $57 \%$.

\section{References}

[1]. Mike Hightower and Gary Brown(2004), Evaporation Suppression Research and Applications for water management, Identifying Technologies to Improve Regional Water Stewardship: North-Middle Rio Grande Corridor.

[2]. Emma Prime et al. (2012),New Technology to reduce Evaporation from Large Water Storages.

[3]. Hardyw, B.,(1919), The Tension of Composite Fluid Surfaces and the Mechanical Stability,(1913),The Tension of Composite Fluid Surface,No.2 .Proc, Roy.Soc., Ser. A., Vol.88.

[4]. LANGMUIR, I. (1917), The shapes of group molecules forming the surfaces of liquids. Proc. Nat. Acad. Sci., vol. 3, no. 4, p. $251-7$.

[5]. Finn, N. and Barnes, S. (2007). The benefits of shade-cloth covers for potable water storages. CSIRO Textile and Fibre Technology.

[6]. MartínezÁlvarez, V., González-Real, M.M. Baille, A. and Molina Martínez, J.M. 2007. A novel approach for estimating the pan coefficient of irrigation water reservoirs: Application to South Eastern Spain. Agricultural Water Management.

[7]. Howard, E. and Schmidt, E. (2008). Evaporation control using Rio Tinto's Floating Modules on Northparks Mine, Landloch and NCEA. National Centre for Engineering in Agriculture Publication 1001858/1, USQ, Toowoomba.

[8]. Heymann, E., and Yoffe, A., 1942, Tie stability of multimolecularfilms of hydrocarbon oils, containingspreaders, on water surfaces: Faraday Soc. Trans.,v. 38, p. 408-417.

[9]. Heymann, E., and Yoffe, A., 1943, The equilibrium betweenlens and unilayer in the system hydrocarbonoil-oleic acid-water, in relation to the interfacial film:Faraday Soc. Trans., v. 39, p. 217-219.

[10]. Stephen R. Turns(2000),An Introduction to Combustion: Concepts and Applications, Second Edition,McGraw-Hill Higher Education. 